\title{
Placement of a Biliary Catheter in the Pancreatic Duct to Aid Common Bile Duct Cannulation
}

Occasionally, cannulation of the common bile duct (CBD) can prove difficult [1]. Several methods have been employed to achieve deep cannulation of the CBD when cannulation with a standard catheter fails, including change in endoscope position; close-up approach to the papilla, using a sphincterotome-like bowing catheter; placing of a wire through either a catheter or a sphincterotome; and using sphincterotomes with different configurations [1,2]. When these techniques fail, and access to the CBD is essential for a therapeutic procedure such as stone extraction, many experts proceed to precut sphincterotomy, but this has the highest complication rate of any CBD cannulation technique [1-3]. We have developed a technique that has allowed us to achieve deep CBD cannulation in three patients after various $C B D$ access techniques had been unsuccessful. A wire with a floppy tip (Hybrid; Wilson Cook, WinstonSalem, North Carolina, USA) is advanced into the pancreatic duct. A biliary catheter is then advanced over the wire and placed $4-5 \mathrm{~cm}$ into the pancreatic duct, and the wire is removed. A sphincterotome preloaded with this guide wire is then introduced through the working channel of the duodenoscope, alongside the biliary catheter which goes to the pancreatic duct (Figure 1). Once the sphincterotome has exited the endoscope, the wire is advanced slightly outside the sphinctero-

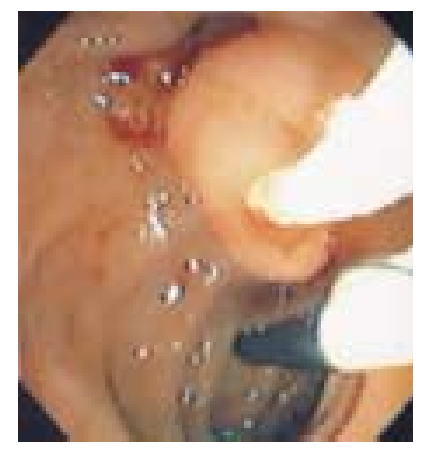

Figure 1 A biliary catheter has been placed in the pancreatic duct, over a guide wire which was then removed. A sphincterotome can be seen exiting the working channel of a duodenoscope in parallel with the biliary catheter. tome. The tip of the wire is then placed into the papillary orifice and carefully advanced into the common channel, alongside the biliary catheter. The biliary catheter left inside the pancreatic duct serves two purposes: acting as a fluoroscopic and endoscopic "road map"; and partially occluding the pancreatic duct, impeding any entry of the guide wire into that duct (Figure 2). This occlusion makes it more likely that the floppy tip of the guide wire will deflect away, facilitating passage of the wire into the CBD. There are two other potential variations of this technique. The first is to access the pancreatic duct with a wire only, which acts as a radiological marker for the pancreatic duct and facilitates endoscopic location of the biliary orifice. The novel concept in our approach is that the biliary catheter partially occludes the pancreatic duct, impeding any entrance of the guide wire into it, and diverting the wire into the CBD. The second variation is to put a plastic stent into the pancreatic duct, and then attempt cannulation in a similar fashion to our technique, or to perform a

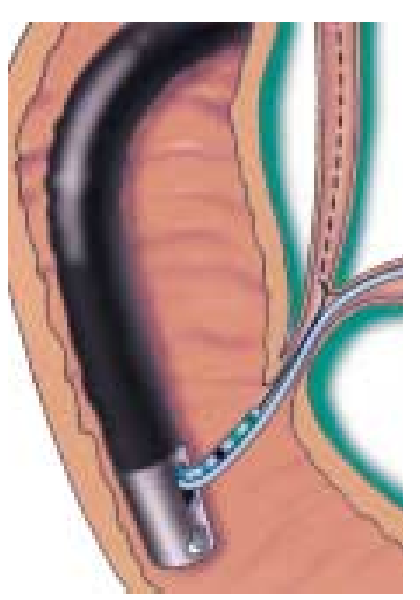

Figure 2 Position of the sphincterotome as it exits the working channel of the duodenoscope in parallel with the biliary catheter, which is in the pancreatic duct. The biliary catheter partially occludes the pancreatic duct, impeding any passage of the guide wire into the pancreatic duct. As the guide wire is slowly advanced into the common channel, the floppy tip deflects away from the catheter which is inside the pancreatic duct, facilitating cannulation of the common bile duct. precut over the stent and then attempt cannulation [4]. This latter approach has proved helpful in cases when the papilla is within a periampullary diverticulum, because the stent can keep the papilla out of the duodenal diverticulum [4]. We conclude that our technique is a useful option in cases of difficult CBD cannulation. The advent of endoscopes with larger channels has made it easier to place several wires and/or catheters into the working channel of the duodenoscope and to manipulate them with ease.

\section{C. Fry, J. A. Barriga, J. D. Linder, K. E. Mönkemüller}

Division of Gastroenterology,

VA Medical Center, University of Alabama, Birmingham, Alabama, USA

\section{References}

${ }^{1}$ Cotton P, Williams C. ERCP Diagnostic technique. In: Practical Gastrointestinal Endoscopy. Oxford: Blackwell Science 1996; 4th ed; 6: 105-138

2 Parasher VD. The difficult bile duct cannulation. In: Bhutani MS, Tandon RK (eds). Advances in gastrointestinal endoscopy. New Delhi: Jaypee Brothers Medical Publishers 2001; 14: 207-226

${ }^{3}$ Huibregtse K, Katon RM, Tytgat GNJ. Precut papillotomy via the needle knife papillotome - a safe and effective technique. Gastrointest Endosc 1986; 32: 403-405

${ }^{4}$ Fogel EL, Sherman S, Lehman GA. Increased selective biliary cannulation rates in the setting of periampullary diverticula: main pancreatic duct stent placement followed by pre-cut biliary sphincterotomy. Gastrointest Endosc 1998; 47: $396-400$

\section{Corresponding Author}

\section{K. Mönkemüiller, M.D.}

Division of Gastroenterology University of Alabama

633 ZRB, UAB Station, Birmingham AL 35294, USA

Fax: $\quad+1-205-934-8493$

E-mail: klaus1@uab.edu 